\title{
An Unusual Case of Aldosterone- and Norepinephrine-Secreting Retroperitoneal Leiomyosarcoma
}

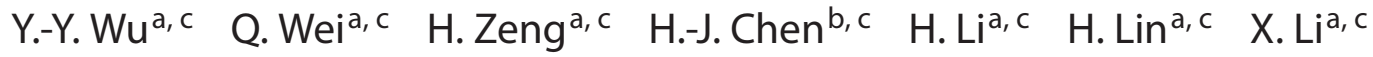 \\ Departments of a Urology and ${ }^{\mathrm{b}}$ Pathology, and ${ }^{\mathrm{C}}$ West China Hospital, Sichuan University, Chengdu, PR China
}

\author{
Key Words \\ Ectopic hormone production - Leiomyosarcoma • \\ Aldosterone $\cdot$ Norepinephrine
}

\begin{abstract}
A case of retroperitoneal leiomyosarcoma (LMS) in a 38-yearold woman who had a tumor in the retroperitoneum with severe hypertension and hypokalemia is presented. Further investigation revealed an elevated serum aldosterone and norepinephrine level. After tumorectomy, the levels of serum aldosterone and norepinephrine successfully normalized; hypertension and hypokalemia were also cured. The tumor was diagnosed as being a LMS by pathologic examination. We suggested that this was the first case of retroperitoneal LMS shown to be associated with increased levels of serum aldosterone and norepinephrine.
\end{abstract}

Copyright $\odot 2008$ S. Karger AG, Basel

\section{Introduction}

Leiomyosarcoma (LMS) of the retroperitoneum, belonging to the soft-tissue sarcomas, is relatively uncommon and comprises less than $1 \%$ of all malignancies [1]. Usually it has non-specific clinical signs and symptoms.
The ectopic hormones secreting LMS is uncommon, especially ectopic catecholamine or aldosterone producing LMS is extremely scarce, and there are no reports. We describe a patient with unusual aldosterone- and norepinephrine-producing retroperitoneal LMS, which was diagnosed by histological and immunohistochemical examination after tumorectomy.

\section{Case Report}

A 38-year-old woman presented symptoms of headache, nocturia and fatigue for 4 months. After admission to the hospital, her blood pressure was 190/130 mm Hg, and her pulse was 120 beats/min. A painless, non-pulsatile, firm abdominal mass was palpable at the middle right abdomen, but no other positive sign was found. Serum biochemistry and hormone tests showed: potassium $2.72 \mathrm{mmol} / \mathrm{l}$, norepinephrine $708 \mathrm{ng} / \mathrm{ml}$, adrenaline $<50$ $\mathrm{ng} / \mathrm{ml}$, and aldosterone in the supine position $452.09 \mathrm{ng} / \mathrm{l}$. Computed tomography (CT) and ultrasound of the abdomen showed normal kidneys and adrenal glands, but a large mass was detected in the middle right retroperitoneal cavity (fig. 1). The mass was measured $5.3 \mathrm{~cm}$ in vertical extension, $6.4 \mathrm{~cm}$ in transverse diameter, and $4.8 \mathrm{~cm}$ in anteroposterior diameter. The patient was diagnosed as 'ectopic pheochromocytoma', and treated with phenoxybenzamine and potassium chloride. Two weeks later, the hypertension was controlled and serum potassium was normal, and the tumor was subsequently resected. After tumorectomy, the tests of serum biochemistry recovered to normal limits: potassi-

\section{KARGER}

Fax +41613061234

E-Mail karger@karger.ch

www.karger.com (c) 2008 S. Karger AG, Basel

$0014-312 X / 08 / 0412-0214 \$ 24.50 / 0$

Accessible online at:

www.karger.com/esr
Xiang Li, MD

Department of Urology, West China Hospital, Sichuan University

Chengdu, Sichuan 610041 (PR China)

Tel. +8628 8542 3465, Fax +862885422451

E-Mail xiangli.87@163.com 

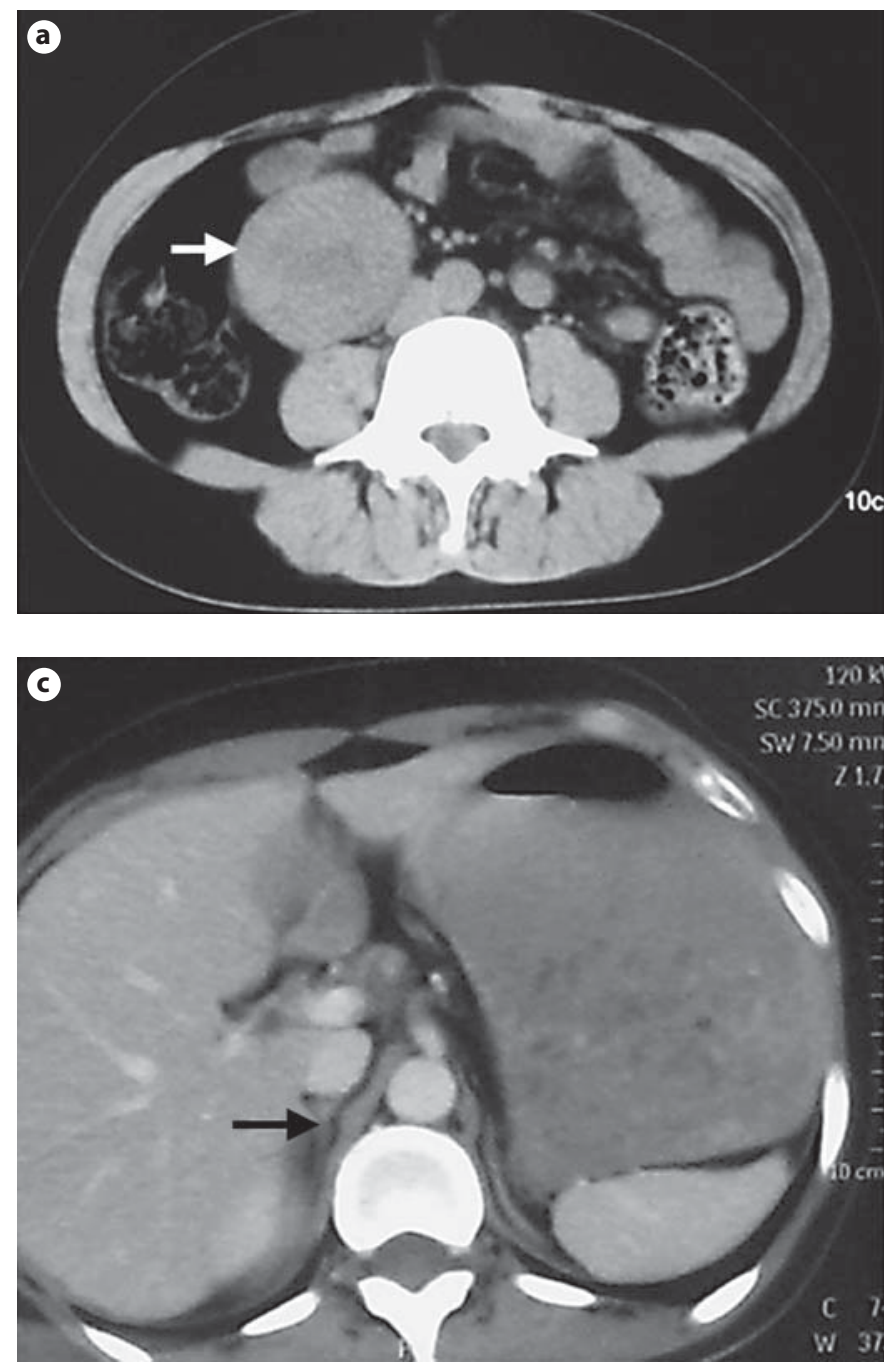

um $3.99 \mathrm{mmol} / \mathrm{l}$, norepinephrine $119 \mathrm{ng} / \mathrm{ml}$, and aldosterone in the supine position $122.7 \mathrm{ng} / \mathrm{l}$. Moreover, hypertension and hypokalemia were cured without application of hypotensive drugs and potassium chloride.

Macroscopically, the tumor mass measured $7 \times 6 \times 4.5 \mathrm{~cm}$, was well-circumscribed, lobular, and grey-white in color. On the cut surface the tumor was white as well as firm with foci of yellow and soft areas. Microscopically, the tumor was composed of spindle-shaped cells with abundant eosinophilic cytoplasm and elongated nuclei (fig. 2a, b). Most nuclei were centrally located and blunt-ended and had a 'cigar-shaped' appearance (fig. 2b). In some areas of the tumor, nuclear hyperchromatism and pleomorphism were notable and multinucleated giant cells were also readily seen. The spindle-shaped cells, slender or slightly plump, were arranged in fascicles intersecting at right angles (fig. 2a). The tumor was compactly cellular, but myxoid change was focally present with a reticular hypocellular appearance. The coagulative necrosis was evident. Mitotic figures were over 15/10 high-power fields (HPF), and atypical mitoses were often seen. Immunohis-

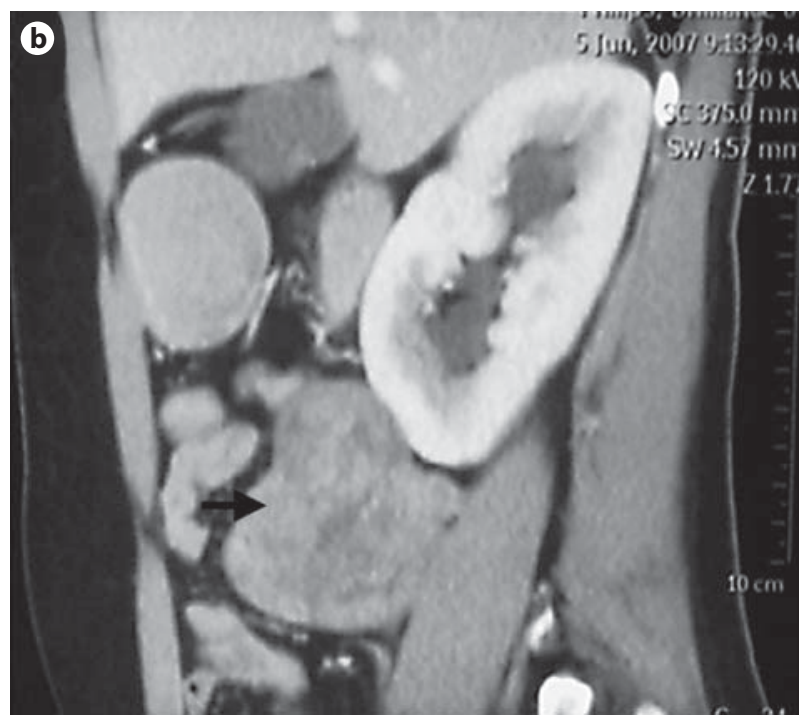

Fig. 1. CT findings. a Non-contrast CT image shows an abnormal soft-tissue mass (arrow) in the retroperitoneal. b Contrastenhanced CT image shows a complex non-uniform enhancing mass (arrow) under the kidney. c Normal adrenal (arrow) was detected. tochemically, tumor cells were diffusely and strongly positive for desmin, SMA and caldesmon, focally positive for CD34 and EMA, while S-100 and CD117 were negative (fig. $2 c-f$ ). The percentage of positive tumor cells for Ki-67 was about $25 \%$. Thus, the tumor was diagnosed as LMS.

\section{Discussion}

LMS of soft tissue, usually located in the retroperitoneum, is a relatively unusual mesenchymal tumor that exhibits smooth-muscle differentiation. It showed both a typical cytologic feature, such as spindle-shaped cells with eosinophilic cytoplasm and elongated 'cigar-shaped' nuclei, and an architectural feature, a fascicular growth pattern. Nevertheless, these features of soft-tissue LMSs 

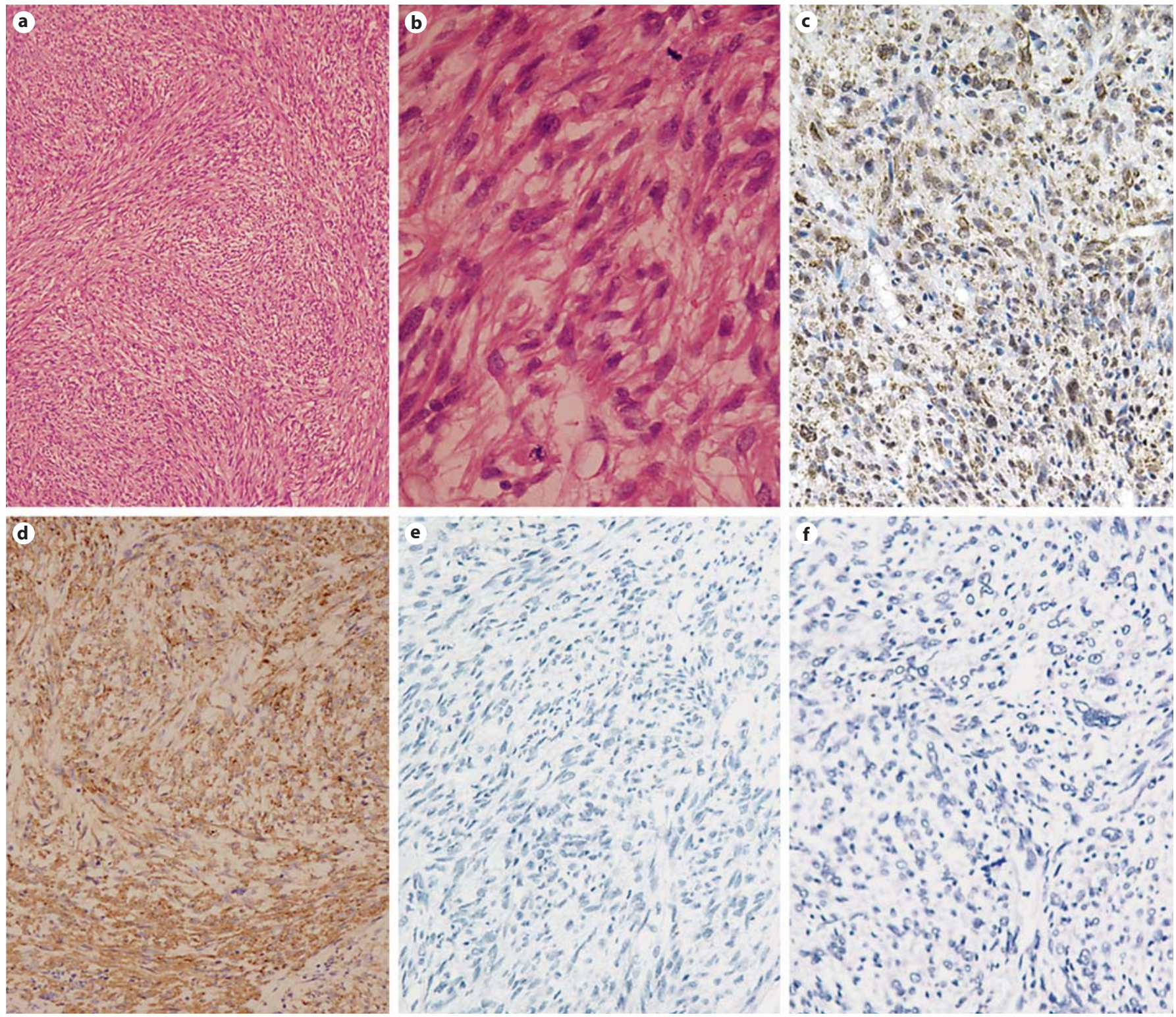

Fig. 2. Histopathologic features of the retroperitoneal LMS. a Histologic features: the tumor is composed of spindle cells with eosinophilic cytoplasm and the cells' fascicles intersect at a right angle $(\times 100)$. b Cytologic features: the tumor shows blunt-ended nuclei with a 'cigar-shaped' appearance; atypical mitoses were readily seen $(\times 200)$. c-f Immunohistochemistry: spindle-shaped tumor cells show immunoreactivity against desmin and SMA, but not against S-100 or CD117 (c desmin, d SMA, e S-100, f CD117; ×200).

may also occur in other spindle cell tumors, such as myofibroblastic tumors, fibrosarcomas, solitary fibrous tumors (SFTs), malignant peripheral nerve sheath tumors (MPNSTs), extragastrointestinal stromal tumors (EGISTs), dedifferentiated liposarcomas, leiomyomas, and so on. Mostly, the cytologic and architectural features mentioned above could play an important role in the differential diagnosis. Besides these features, in most instances, immunohistochemistry may provide another useful clue to the differential diagnosis. The immunoreactivity of desmin, a specific marker of muscle cell differentiation, is rarely detectable in myofibroblastic tumors and fibrosarcomas, but is encountered, usually strongly and diffusely, in myogenic neoplasms, such as 
LMSs. MPNSTs do not show immunoreactivity for desmin, but may display variable S-100 positivity. SFTs characteristically express CD34 and CD99, but do not or only focally and limitedly express desmin [2,3]. Most EGISTs are positive for CD117 (c-Kit, a receptor tyrosine kinase encoded from the $c$-kit proto-oncogene) and CD34, and only less than 5\% of EGISTs show reactivity for desmin focally [4]. Dedifferentiated liposarcoma is composed of spindle cells and may show myogenic differentiation as being desmin-positive, but it is usually a typically abrupt transition between the well-differentiated liposarcoma and non-lipogenic area. Thus, both the histologic and immuophenotypic features reliably allow LMSs to differentiate from other spindle-shaped tumor cells. Differentiation between leiomyomas and LMSs of soft tissue may be difficult. Histological assessment of malignancy includes mitotic activity, cellularity, atypia and necrosis. The mitotic activity is the main criterion, namely those tumors with $>5$ mitoses per $10 \mathrm{HPF}$ are considered malignant. Nuclear antigen Ki-67, which is associated with cell proliferation, is found to be significantly elevated in LMSs, and could be used as an immunohistochemical marker to distinguish between LMSs and leiomyomas [5]. In this case, the tumor shows as histologic features spindle-shaped cells with abundant eosinophilic cytoplasm, elongated nuclei and $>15$ mitoses per $10 \mathrm{HPF}$ (fig. 2a). The immunoreactivity characteristics of the tumor were strongly and diffusely expression of desmin, SMA and caldesmon, but negative of S-100 and CD117 (fig. 2c-f). Thus, the tumor was diagnosed as LMS.

Typically, retroperitoneal LMSs have vague presenting symptoms. Moreover, LMSs have rarely produced ectopic hormones, such as $\beta$-HCG [6-8], insulin-like growth factor 2 [9], parathyroid hormone [10], and renin [11-13].
Hormone-secreting LMSs may originate from the small intestine, transverse colon, spermatic cord, thorax, or chest wall [7]. There were some case reports of retroperitoneal LMS which secreted renin and caused severe hypertension [11-13]. In view of the high norepinephrine and aldosterone serum level in this patient and the normal limit of hormones after tumorectomy, we believed that this tumor was associated with producing norepinephrine and aldosterone which led to the clinical manifestation of hypertension and hypokalemia. In order to declare the characteristics of the tumor, histological and immunohistochemical examinations were performed, and LMS was diagnosed. To our knowledge, this is the first case report to describe aldosterone- and norepinephrine-secreting retroperitoneal LMS - a new kind of ectopic hormone producing LMS.

Frequently, aldosterone- and norepinephrine-secreting tumors originate from the adrenal gland. Ectopic norepinephrine-secreting tumors are unusual, except ectopic pheochromocytomas. Uede et al. [14] described a case of malignant mixed mesodermal tumor of the uterine corpus with hypercatecholaminemia. It seemed to show that a tumor of mesenchymal origin may produce catecholamine, such as norepinephrine and adrenaline. Ectopic aldosterone-producing tumors are scarce; only a few cases, located in the retrocaval region [15] and ovaries $[16,17]$, have been described. Up to now, no aldosteroneproducing LMS has been presented. This is the first case of a retroperitoneal LMS shown to be associated with increased levels of serum aldosterone and norepinephrine. Moreover, it has reminded us that LMS, as a kind of tumor of mesenchymal origin, has an extensively variable ectopic hormone production and clinical manifestation.

\section{References}

- 1 Fisher NW, Nutinsky CL: Retroperitoneal leiomyosarcoma: a review of the literature. J Am Osteopath Assoc 1989;89:1058-1060.

-2 Van de Rijn M, Lombard CM, Rouse RV: Expression of CD34 by solitary fibrous tumor of the pleura, mediastinum, and lung. Am J Surg Pathol 1994;18:814-820.

-3 Krishnakumar S, Subramanian N, Mohan ER, Mahesh L, Biswas J, Rao NA: Solitary fibrous tumor of the orbit: a clinicopathologic study of six cases with review of the literature. Surv Ophthalmol 2003;48:544-554.
4 Miettinen M, Majidi M, Lasota J: Pathology and diagnostic criteria of gastrointestinal stromal tumors (GISTs): a review. Eur J Cancer 2002;38(suppl 5):S39-S51.

5 Mayerhofer K, Lozanov P, Bodner K, Bodner-Adler B, Kimberger O, Czerwenka K: Ki-67 expression in patients with uterine leiomyomas, uterine smooth muscle tumors of uncertain malignant potential and uterine leiomyosarcomas. Acta Obstet Gynecol Scand 2004;83:1085-1088.

6 Mansi IS, Ashley I, Glezerov V: Retroperitoneal leiomyosarcoma and enlarged epididymis associated with a positive pregnancy test. Am J Med Sci 2002;324:104-105.
7 Meredith RF, Wagman LD, Piper JA, Mills AS, Neifeld JP: Beta-chain human chorionic gonadotropin-producing leiomyosarcoma of the small intestine. Cancer 1986;58:131135.

$\rightarrow 8$ Seidl C, Lippert C, Grouls V, Jellinghaus W: Leiomyosarcoma of the spermatic cord with paraneoplastic $\beta$-HCG production. Pathologe 1998;19:146-150.

$\checkmark 9$ Daughaday WH, Emanuele MA, Brooks MH, Barbato AL, Kapadia M, Rotwein P: Synthesis and secretion of insulin-like growth factor II by a leiomyosarcoma with associated hypoglycemia. N Engl J Med 1988;319:1434-1440. 
10 Robin NI, Siegel LM, Hawker CD, Magida MG: Hypercalcemia and metastatic intestinal leiomyosarcoma: a case of ectopic parathyroid hormone production. Conn Med 1976;40:609-611.

-11 Moody AM, Ahmed A, Chakrabarty A, Fisher C: Renin-producing leiomyosarcoma originating in the uterus. Clin Oncol 1995; 7: $52-53$.

-12 Kawai K, Fukamizu A, Kawakami Y, Matsumura M, Mitsui K, Murakami K, Yamashita K: A case of renin-producing leiomyosarcoma originating in the lung. Endocrinol Jpn 1991;38:603-609.
3 Geddy PM, Main J: Renin-secreting retroperitoneal leiomyosarcoma: an unusual cause of hypertension. J Hum Hypertens 1990;4:57-58.

14 Uede T, Saito T, Minase T, Miura T, Kikuchi $\mathrm{K}$, Iimura O, Kon S, Iwaki H, Mori M: A malignant mixed mesodermal tumor of the uterine corpus with hypercatecholaminemia. Acta Pathol Jpn 1990;40:293-300.
15 Mazza E, Papotti M, Durando R, Robecchi A, Camanni F: Ectopic aldosteronoma associated to another adrenocortical adenoma in the adrenal gland of the same side. J Endocrinol Invest 1995; 18:809-812.

16 Jackson B, Valentine R, Wagner G: Primary aldosteronism due to a malignant ovarian tumour. Aust NZ J Med 1986;16:69-71.

17 Todesco S, Terribile V, Borsatti A, Mantero F: Primary aldosteronism due to a malignant ovarian tumor. J Clin Endocrinol Metab 1975;41:809-819. 